\title{
BAUMANN, Imanuel, Dem Verbrechen auf der Spur. Eine Geschichte der Kriminologie und Kriminalpolitik in Deutschland 1880 bis 1980
}

\section{Falk Bretschneider}

\section{OpenEdition}

Édition électronique

URL : http://journals.openedition.org/ifha/764

DOI : $10.4000 /$ ifha.764

ISSN : 2198-8943

Éditeur

IFRA - Institut franco-allemand (sciences historiques et sociales)

Référence électronique

Falk Bretschneider, «BAUMANN, Imanuel, Dem Verbrechen auf der Spur. Eine Geschichte der Kriminologie und Kriminalpolitik in Deutschland 1880 bis 1980 », Revue de I'IFHA [En ligne], Date de recension, mis en ligne le 01 janvier 2006, consulté le 22 septembre 2020. URL : http://journals.openedition.org/ifha/764 ; DOI : https://doi.org/10.4000/ifha.764

Ce document a été généré automatiquement le 22 septembre 2020.

(CIFHA 


\section{BAUMANN, Imanuel, Dem Verbrechen auf der Spur. Eine Geschichte der Kriminologie und Kriminalpolitik in Deutschland 1880 bis 1980}

Falk Bretschneider

Quand Karli Schuler fut condamné pour la quatrième fois, en 1956, pour un délit mineur, le médecin de la prison de Fribourg-en-Brisgau nota, à l'arrivée du jeune criminel en détention, que celui-ci, «psychopathe affirmé », serait « bien porteur d'une prédisposition héréditaire » (p. 357). Une telle interprétation du fait criminel par des catégories médico-psychiatriques ne surprend-elle pas à un moment où l'Allemagne (de l'Ouest) semblait s'être libérée des pires excès d'une criminologie fondée sur des concepts biologiques, telle qu'elle s'était pratiquée pendant la période nazie ? C'est l'une des questions que se pose I.B. dans son étude, qui entreprend, pour la première fois et après les quelques ouvrages parus ces dernières années sur l'histoire de la criminologie allemande du XIXe et de la première moitié du XXe s. (P. Becker, S. Galassi, R. Wetzell, Ch. Müller [voir BullMHFA, 41, 2005, p. 469-471]), une analyse historiographique de l'évolution prise Outre-Rhin par la science criminologique après 1945. L'auteur se fixe d'une part pour objectif de vérifier une interprétation courante (surtout chez les contemporains), à savoir celle du « nouveau départ » (Neubeginn) de la criminologie allemande après la chute du régime nazi. Il se pose également la question du bien-fondé d'une autre interprétation habituelle qui est, si l'on veut, l'inverse de la première : la génération de 68 a-t-elle réussi, comme l'ont prétendu plusieurs criminologues réformés de l'époque, à renouveler profondément la science criminologique allemande par la réception de concepts sociologiques développés, depuis des années 1930, aux États-Unis?

2 Le texte se divise en trois parties, toutes marquées par une approche biographique qui dévoile une science portée par des hommes (et quelques femmes) et non seulement par des « idées ». Dans la première, I.B. retrace la naissance de la criminologie à partir des 
années 1880. Comme d'autres avant lui, il montre, à l'échelle internationale, l'émergence d'un modèle interprétatif qui tourne autour des notions de " prédisposition » (Anlage) et d'« environnement " (Umwelt). Le concept-clé de l'« infériorité psychopathique " et les méthodes eugéniques sont les signes d'une " biologisation du social " généralisée dans les années 1920 (p. 59) partout en Europe et aux États-Unis. En Allemagne, ils deviennent les bases d'une "radicalisation des options » (p. 69) bien avant que, à partir de 1933, le " discours de sélection " se transforme, dans la politique national-socialiste, en une " pratique d'exclusion » (p. 79) avec des résultats meurtriers. Cette préexistence d'une approche biologique de la criminologie pendant les années de la République de Weimar explique également, ce que montre I.B. dans la deuxième partie, une tradition intacte dans les paradigmes de la discipline après la fin de la guerre.

L'an 1945 ne constitue donc pas de rupture dans les pratiques pénales (p. 126), ni dans leurs fondements criminologiques, ni d'ailleurs dans les biographies d'importants acteurs (p. 151-166). Bien que la stérilisation et l'exécution des criminels ne soient plus pratiquées, les contemporains regrettent parfois les camps de concentration pour jeunes délinquants, perpétuent la tradition d'une perception discriminatoire des tziganes et déplorent la libération par les Alliés des criminels internés des camps (p. 217-223, 226-229). Cependant, à la fin des années 1950, dans une République fédérale politiquement et socialement stabilisée, les anciens concepts commencent à perdre en influence. Dans la troisième partie, I.B. déploie un éventail d'approches réformatrices auxquelles ont participé aussi bien d'anciens protagonistes de la science criminologique allemande des années 1940 et 1950 (T. Würtenberger) que de jeunes criminologues animés par une expérience d'études aux États-Unis (F. Sack). Là aussi, la rupture construite rétrospectivement par certains acteurs n'en est guère une. L'ouverture de la criminologie allemande vers la recherche internationale, la psychanalyse et surtout la sociologie (Durkheim, la Chicago school) débute bien avant la date-phare de 1968 : le changement de paradigme criminologique et l'émergence de nouvelles façons de penser (surtout par le concept de la labeling approach) se sont produits, démontre l'auteur, d'une manière non pas abrupte, mais « insidieuse » (p. 273).

4 L'étude d'I.B. rassemble un grand nombre de nouvelles informations et permet de réévaluer profondément l'image qu'avait jusqu'ici l'historiographie de l'évolution de la criminologie allemande au XXe s. Les thèses qu'avance l'auteur sont formulées clairement et vigoureusement, les résultats qu'il apporte à ses questions sont empiriquement convaincants. On regrette seulement une chose : que l'auteur n'ait pas remplacé la partie sur les années 1880-1945, période sur laquelle nous sommes bien informés par d'autres recherches auxquels I.B. n'apporte pas vraiment de nouveaux résultats, par une étude comparative sur la criminologie "socialiste » dans la zone orientale de l'Allemagne puis en R.D.A.

Falk BRETSCHNEIDER (Centre Interdisciplinaire d'Études et

de Recherches sur l'Allemagne, Paris) 